\title{
Soft X-ray XAFS Analysis of Cluster Formation Behavior during Natural Aging on an Al-Mg-Si Alloy*1
}

\author{
Serina Tanaka*2, Hiroki Adachi and Takehiro Nonomura*3 \\ Graduate School of Engineering, University of Hyogo, Himeji 671-2280, Japan
}

\begin{abstract}
This study investigated cluster formation in the early stages of natural aging in Al-1.04 mass $\% \mathrm{Si}-0.55 \mathrm{mass} \% \mathrm{Mg}$ alloys by soft $\mathrm{X}$-ray XAFS measurements and first-principles calculation. XAFS measurements at the Mg-K and Si-K edges were carried out at the BL27SU beamline at SPring-8. It was found that the absorption edge energies changed as aging proceeded. Density functional theory (DFT) calculations were used to determine the valence electron densities near $\mathrm{Si}$ and $\mathrm{Mg}$ atoms and to simulate the Si-K and $\mathrm{Mg}-\mathrm{K}$ edge spectra for some cluster models. On the basis of the results, it was demonstrated that $\mathrm{Si}$ and $\mathrm{Mg}$ atoms formed clusters in four stages (I-IV) during natural aging. In stage I, Si-vacancy pairs, Mg-vacancy pairs, and a combination of both were formed. In stage II, vacancies were released from the clusters formed in stage I. In stage III, Mg-vacancy pairs were included in the clusters. In stage IV, the clusters coarsened through the release of vacancies. These results indicate that soft X-ray XAFS, which is capable of identifying individual elements, has the ability to provide information on such clusters. [doi:10.2320/matertrans.MT-L2021004]
\end{abstract}

(Received May 10, 2021; Accepted July 6, 2021; Published September 25, 2021)

Keywords: Al-Mg-Si alloys, clusters, XAFS

\section{Introduction}

Aluminum is used as a structural material in various application because of light weight, excellent recycling efficiency and high specific strength that can be improved by alloying. Recently, Al-Mg-Si alloys have been paid much attention and developed for automobiles as body-panel materials. The preference selection of $\mathrm{Al}-\mathrm{Mg}-\mathrm{Si}$ alloys is due to bake-hardening, because the alloys are precipitationstrengthening-type alloy, in which $\beta^{\prime \prime}$ phase that contributes to hardening precipitates by artificial aging at about $443 \mathrm{~K}$ for $1.2 \sim 3.6 \mathrm{ks}$, following the solid solution treatment. However, the bake-hardening effect is diminished by natural aging (NA) following a solution treatment. This phenomenon is a known negative effect in two-step aging. ${ }^{1-5)}$ In general, the cluster (1) is formed during NA following the solid solution treatment. The formed clusters bring negative effect to age-hardening in next artificial aging process. When applying aging to the solid-solution-treated sample immediately at temperatures range about from $443 \mathrm{~K}$ to $373 \mathrm{~K}$, the cluster (2) is formed. This type of cluster causes positive effect on the next artificial age-hardening. These negative and positive effects are attributed to inhibition of $\beta^{\prime \prime}$ phase formation by the cluster (1) and promotion of the formation by the cluster (2) which can be act as nucleation sites of $\beta^{\prime \prime}$ phase. $^{1-6)}$

These clusters in Al-Mg-Si alloys have been studied using transmission electron microscopy (TEM), ${ }^{7,8)} \mathrm{X}$-ray diffraction (XRD), ${ }^{9,10)}$ small-angle X-ray scattering (SAXS), ${ }^{11,12)}$ differential scanning calorimetry (DSC), ${ }^{2,4,6,13-15)}$ electrical resistivity measurements, ${ }^{2,4,6)}$ positron annihilation lifetime spectroscopy (PALS), ${ }^{16,17)}$ and atom-probe tomography (APT) ${ }^{3,6,18,19)}$ The clusters are an aggregate structure that consist of solute atoms and vacancies. They have quite

\footnotetext{
${ }^{* 1}$ This Paper was Originally Published in Japanese in J. JILM 71 (2021) 144-151.

${ }^{* 2}$ Graduate Student, University of Hyogo

${ }^{* 3}$ Graduate Student. Present address: Nippon Steel Corporation, Kashima 314-0014, Japan
}

similar structures with a matrix of the alloy, further does not possess regular long-range order. Therefore, structural analysis based on XRD is not available and the analysis using TEM observation is also difficult. Information of the cluster such as containing elements and local structures cannot be obtained by electrical resistivity measurement and DSC. In addition, SAXS peaks are not observed because the atomic numbers of the constituent elements are close each other and difference of electron densities between the matrix and the cluster is also small. ${ }^{20,21)}$ APT has the advantage of providing composition information about clusters. However, it is difficult to obtain influence of microalloying elements as statistical information and to investigate cluster formation process in the early stage of the aging, because atomic yield reaches only about $50 \%$ and also sample preparation needs long time. PALS has the advantage to be able to obtain information about vacancies in the clusters. Information about the elements that exist in neighbor of the vacancy can be investigated by the changes in positron life time and the Doppler analysis. Banhart et al. ${ }^{16)}$ have revealed four stages of changes in the lifetime of positrons during progress of NA in 6082 alloy $\left(\mathrm{X}_{\mathrm{Mg}}=0.63\right.$ mass $\%, \mathrm{X}_{\mathrm{Si}}=0.83$ mass $\%, \mathrm{X}_{\mathrm{Cu}}<$ 0.24 mass \%). Further, Liu et al. ${ }^{17)}$ confirmed such four stages changes in $\mathrm{Al}-0.37 \mathrm{Mg}-0.86 \mathrm{Si}$ (mass\%) and $\mathrm{Al}-0.51 \mathrm{Mg}-$ 0.69Si (mass\%). However, both of the research groups reported different explanations for the phenomena of especially about the stage I and stage II. This disagreement seems to be due to difficulty of understanding the cluster formation from information in the neighborhood of vacancies only, since information about not adjacent solute atoms cannot be obtained by PALS.

For the aforementioned reasons, much knowledge has been obtained about clusters in $\mathrm{Al}-\mathrm{Mg}-\mathrm{Si}$ alloys using various techniques; however, numerous aspects of the cluster formation behavior are unclear, especially those in the early stage of aging.

In the present study, X-ray absorption fine structure (XAFS) measurements, which help clarify the structure and electronic structure around specific atoms, was used as a new 


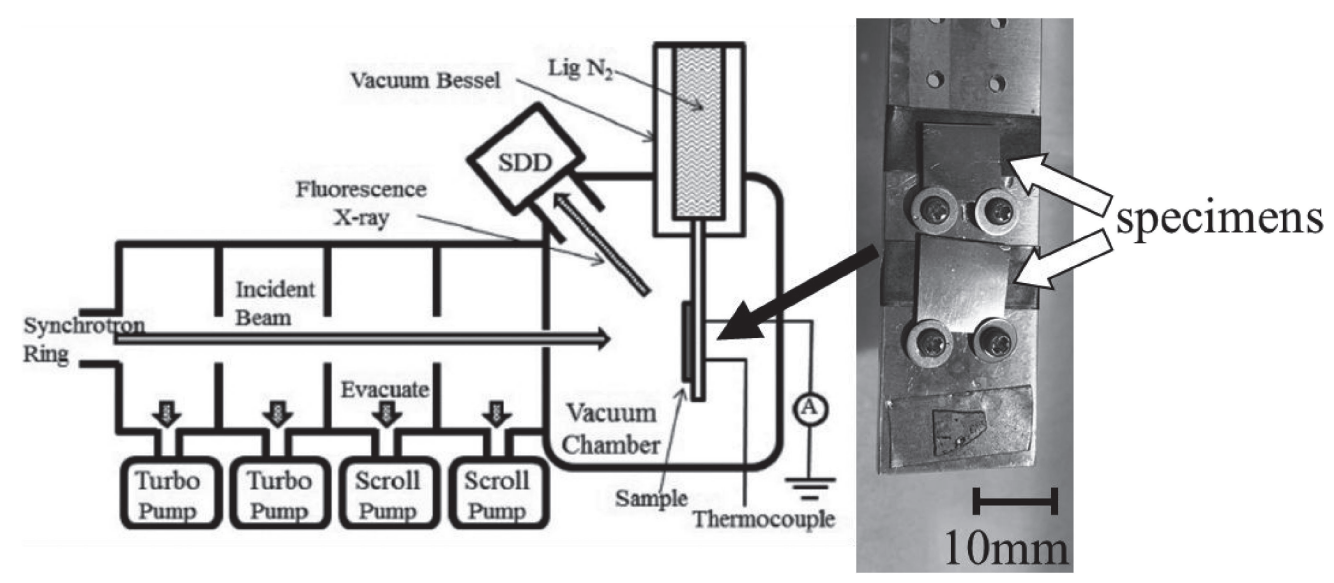

Fig. 1 Schematic of the XAFS apparatus at BL27SU beamline at SPring-8.

method investigate clusters. However, XAFS measurements require soft X-rays because the edge energy of $\mathrm{Al}, \mathrm{Mg}$, and $\mathrm{Si}$ is $1.3-1.8 \mathrm{keV}$. XAFS spectra are divided into an XANES (X-ray absorption near edge structure) spectrum corresponding to the region near the absorption edge to $50 \mathrm{eV}$ and an EXAFS (extended XAFS) spectrum from 100 to $1000 \mathrm{eV}$. The absorption edge of atoms and their valence are closely related: the edge energy shifts toward higher energies when the valence of atoms increases and toward lower energies when the valence of atoms decreases. ${ }^{22-24)}$ Adachi et al. ${ }^{25)}$ used soft-X-ray XAFS measurements to investigate the limited structure around $\mathrm{Si}$ and $\mathrm{Mg}$ atoms in Cluster (1) and Cluster (2) formed in $\mathrm{Al}-0.54 \mathrm{Mg}-0.97 \mathrm{Si}$ (mass\%). As a result, they clarified that Cluster (1) is formed by both $\mathrm{Si}$ and $\mathrm{Mg}$ atoms and that $\mathrm{Si}$ atoms in Cluster (1) have bonds with high ionic character. However, the structural changes that occur in clusters as aging progress are unclear, especially in the early stage of aging. In the present study, the cluster formation behavior the NA process around $\mathrm{Si}$ atoms and $\mathrm{Mg}$ atoms in the $\mathrm{Al}-\mathrm{Mg}-\mathrm{Si}$ alloys was investigated by observing changes in the absorption edge energy and spectral shapes in XANES spectra by soft X-ray XAFS analysis.

\section{Experimental Procedure}

Excess-Si-type Al-1.04 mass $\% \mathrm{Si}-0.55$ mass $\% \mathrm{Mg}$ alloys provided by UACJ Corp. were used in the present study; the sample dimensions were $10 \times 10 \times 1 \mathrm{~mm}^{3}$. A solution heat treatment was carried out for $0.6 \mathrm{ks}$ at $823 \mathrm{~K}$ by the electric furnace, and the samples were, subsequently quenched in ice-water. These specimens are hereafter referred to as-quenched (A.Q.) alloys. The NA was performed at room temperature for durations ranging from $0.6 \mathrm{ks}$ to $8.8 \times 10^{4} \mathrm{ks}$.

NA hardening behavior was evaluated using micro-Vickers hardness measurements conducted on a SHIMADZU HMV2000 (load: $2.452 \mathrm{~N}$, holding time: $10 \mathrm{~s}$ ). The high and low values of seven collected data were discard, and five data were averaged.

Soft-X-ray XAFS measurements were carried out at the BL27SU beamline at SPring- 8 . The XAFS spectra were recorded at the $\mathrm{Si}-\mathrm{K}$ and $\mathrm{Mg}-\mathrm{K}$ edges using a silicon drift detector (SDD). ${ }^{25)}$ High-purity Si, high-purity $\mathrm{Mg}(99.9 \%)$, and binary alloys $\mathrm{Al}-0.5 \mathrm{mass} \% \mathrm{Si}$ and $\mathrm{Al}-0.5 \mathrm{mass} \% \mathrm{Mg}$ were used as samples for comparison. In-situ XAFS measurements were carried out at room temperature from the edge energy to $15 \mathrm{eV}$ when the NA time was $0.6-15 \mathrm{ks}$ to observe changes in the edge energy details because previous reports ${ }^{25}$ have indicated that the magnitude of edge energy changes are small, $(<1.0 \mathrm{eV})$ in the first stage of NA. However, the XAFS spectra were recorded intermittently from the edge energy to $50 \mathrm{eV}$ with liquid $\mathrm{N}_{2}$ cooling when the NA time was longer than $15 \mathrm{ks}$. Figure 1 shows a schematic of the XAFS apparatus. XAFS measurements in the usual transmission mode were difficult because the alloys have a very small quantity of $\mathrm{Si}$ and $\mathrm{Mg}$ and because the $\mathrm{Si}-\mathrm{K}$ and $\mathrm{Mg}-\mathrm{K}$ edge energies are low. Therefore, the measurements were conducted in fluorescence mode, where the intensity of fluorescence X-rays, which are closely related to transmittance were measured.

To estimate the cluster structural changes on the basis of the changes in the XANES spectra, we carried out firstprinciples calculations on the basis of density functional theory (DFT), as implemented in the Advance/PHASE software and calculated by the pseudopotential method using a plane-wave basis set. The Perdew-Burke-Ernzerhof version of the generalized gradient approximation was used to describe the exchange-correlation functional. The cluster model was built in a $3 \times 3 \times 3$ supercell comprising 27 unit cells with 108 atoms as a face-centered cubic Al matrix. The cluster models in which a $\mathrm{Si}$ or $\mathrm{Mg}$ atoms located the center and one of the first-nearest-neighbor atoms was replaced with a $\mathrm{Mg}$ atom, $\mathrm{Si}$ atom, or vacancy (Va) were optimized. The valence electron density around the core atom was calculated to investigate the correlation with the changes in the edge energy in the XANES spectra. For comparison with the results of the experiments, XANES profiles were calculated $^{26-29)}$ for each cluster model. For optimization of the norm-conserving pseudopotential, we used a wave-function cutoff energy of 5 Hartree, a maximum force per one atom of $3.0 \times 10^{-4}$ Hartree, a charge-density cutoff energy of 20 Hartree, and a $k$-point grid with the $4 \times 4 \times 4$ mesh. For the XANES spectra calculations after the optimizations, a corehole pseudopotential was introduced in the $\mathrm{Si}$ atoms of interest, a ground-state pseudopotential was introduced in the $\mathrm{Mg}$ atoms of interest, and a pseudopotential by projectoraugmented wave (PAW) method was introduced in the other 


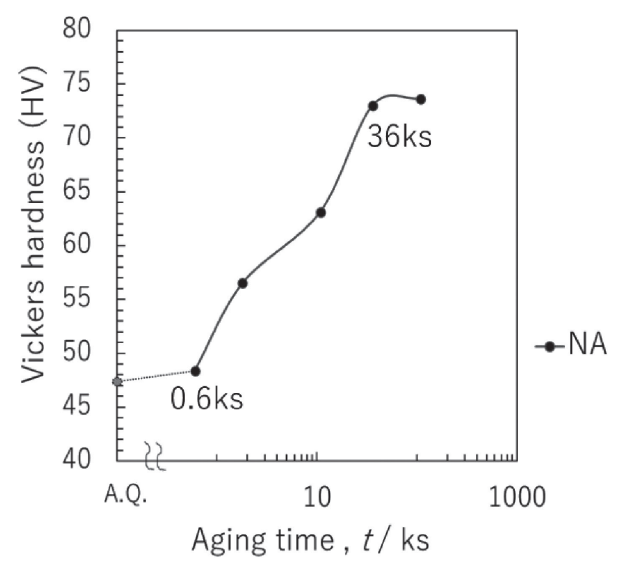

Fig. 2 Vickers hardness variation in Al-1.04 mass $\% \mathrm{Si}-0.55$ mass $\% \mathrm{Mg}$ alloy during natural aging (NA).

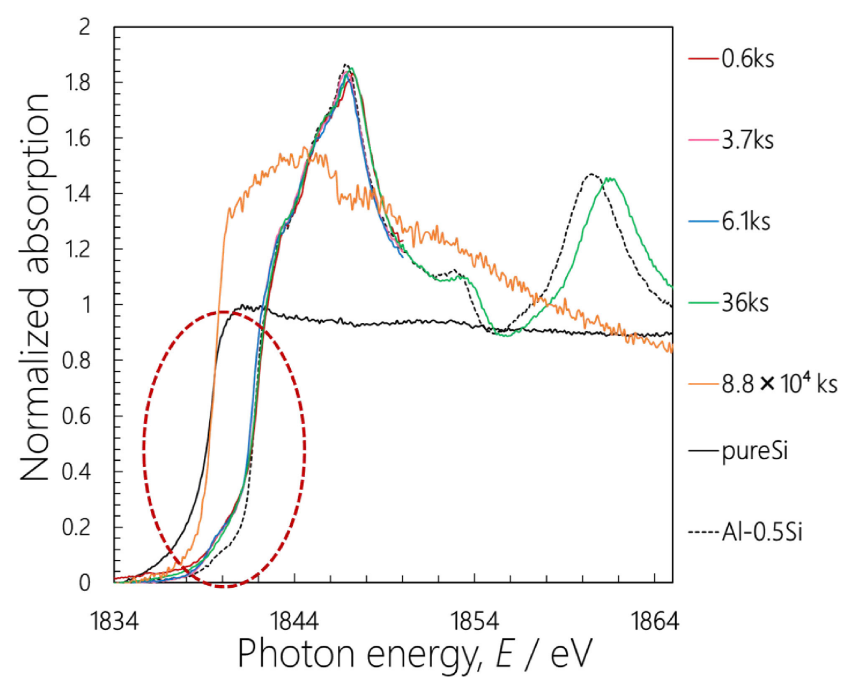

Fig. 3 XANES spectra near $\mathrm{Si}-\mathrm{K}$ edge of $\mathrm{Al}-\mathrm{Mg}-\mathrm{Si}$ alloys and reference samples.

atoms. For calculation of the XANES spectra, we used a wave-function cutoff energy of 8 Hartree, a maximum force per one atom of $1.0 \times 10^{-4}$ Hartree, a charge density cutoff energy of 72 Hartree, and a $k$-point grid with a $4 \times 4 \times 4$ mesh. $^{26-30)}$

\section{Results and Discussions}

\subsection{Hardness measurements}

Figure 2 shows the variation of the Vickers hardness during NA. The hardness increased substantially, by $\sim 25 \mathrm{HV}$, between 0.6 and $36 \mathrm{ks}$ during NA. We speculated that cluster formation progressed during this period. Noting the time interval when the hardness remarkably increased (i.e., from $0.6 \mathrm{ks}$ to $36 \mathrm{ks}$ ), we focused on this time interval in the present study.

\subsection{Evaluation and analysis of nanoclusters by XAFS measurement}

Figure 3 shows NA-induced changes in the normalized XANES spectra near the Si-K edge of Al-Mg-Si alloys and reference samples. The absorption increased when the incident energy exceeded the edge (1836-1842 eV). No major changes in the spectral shapes were observed as aging progressed except in the spectrum of the sample aged for $8.8 \times 10^{4} \mathrm{ks}$; however, after only $0.6 \mathrm{ks}$ of $\mathrm{NA}$, the absorption edge shifted dramatically to the high-energy side compared with the absorption edge of pure $\mathrm{Si}$.

Figure 4 shows expanded spectra near the absorption edge indicated by the red dotted circle in Fig. 3. During NA, the edge energy clearly shifted (a) $0.2 \mathrm{eV}$ toward the high-energy side in the interval from $0.6 \mathrm{ks}$ to $3.7 \mathrm{ks}$, (b) $0.05 \mathrm{eV}$ toward the low-energy side from $3.7 \mathrm{ks}$ to $13.3 \mathrm{ks}$, (c) $0.2 \mathrm{eV}$ toward the high-energy side again from $13.3 \mathrm{ks}$ to $36 \mathrm{ks}$, and (d) $2.3 \mathrm{eV}$ toward the low-energy side again from $36 \mathrm{ks}$ to $8.8 \times 10^{4} \mathrm{ks}$. As such, the Si-K edge energy shift was divided into four stages corresponding to the changes during NA; the results also suggest that the structure around the $\mathrm{Si}$ atoms changed.

Figure 5 shows normalized XANES spectra near the Mg$\mathrm{K}$ edge of $\mathrm{Al}-\mathrm{Mg}-\mathrm{Si}$ alloys and reference samples, revealing the changes that occur during NA. The absorption increased when the incident energy exceeded the Mg-K edge (1300$1312 \mathrm{eV})$. Figure 6 shows expanded spectra near the absorption edge indicated by the red dotted circle in Fig. 5 . During NA, the edge energy clearly shifted (a) $0.3 \mathrm{eV}$ toward the high-energy side from $0.6 \mathrm{ks}$ to $1.8 \mathrm{ks}$, (b) $0.15 \mathrm{eV}$ toward the low-energy side from $1.8 \mathrm{ks}$ to $4.2 \mathrm{ks}$, (c) $1.4 \mathrm{eV}$ toward the high-energy side again from $4.2 \mathrm{ks}$ to $86.4 \mathrm{ks}$, and (d) $3.6 \mathrm{eV}$ toward the low-energy side again from $86.4 \mathrm{ks}$ to $8.8 \times 10^{4} \mathrm{ks}$. As such, the $\mathrm{Mg}-\mathrm{K}$ edge energy shift was divided into four stages corresponding to the changes in $\mathrm{NA}$; the results also suggest that the structure around the $\mathrm{Mg}$ atoms changed.

These shifts in the absorption edge energies starting from the early NA are hereafter referred to as stage I, stage II, stage III and stage IV. Figure 7 shows the relationship between these four stages and the NA time. The shift time from stage I to stage II and that from stage II to stage III differed slightly between the $\mathrm{Si}$ and $\mathrm{Mg}$ spectra. However, whether this difference was a measurement error or an important difference is unclear because the magnitude of the energy shift in each stage in the XAFS measurements was only a few electron volts. By contrast, the end time of stage III did not substantially differ between the $\mathrm{Si}$ and $\mathrm{Mg}$ spectra. Also, the end times of the four stages observed in the PALS ${ }^{16,17)}$ and XAFS spectra were approximately the same. Consequently, the four stages characterized by XAFS measurements were considered to correspond to the changes in cluster formation behavior.

\subsection{Valence electron density calculation of cluster models}

To investigate the cause of the shift in the absorption edge energy, we calculated the changes in the valence electron density of the central $\mathrm{Si}$ and $\mathrm{Mg}$ atoms in an $\mathrm{Al}$ matrix in which one of the first-nearest-neighbor atoms was replaced with an $\mathrm{Al}, \mathrm{Mg}$, or Si atom or a vacancy (Va). Figure 8 shows the change in valence electron density from the core atom to the nearest atom for central atoms. The horizontal axis shows the distance from the core atom to one of the first-nearestneighbor atoms, and the vertical axis shows the valence density. Moreover, the straight lines shown in Fig. $8(\mathrm{X} \simeq$ 
(a)
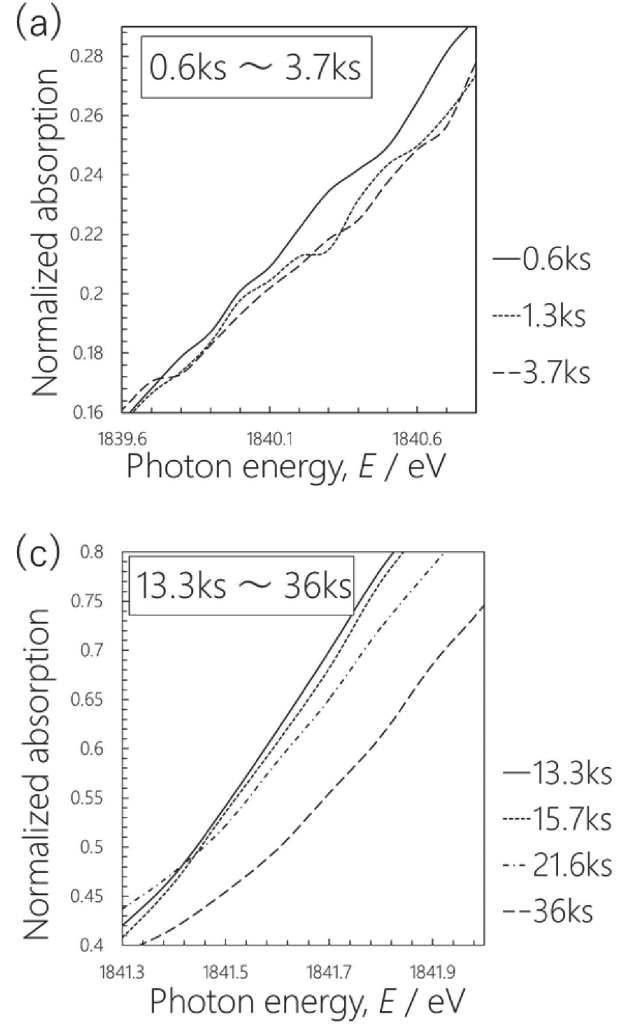
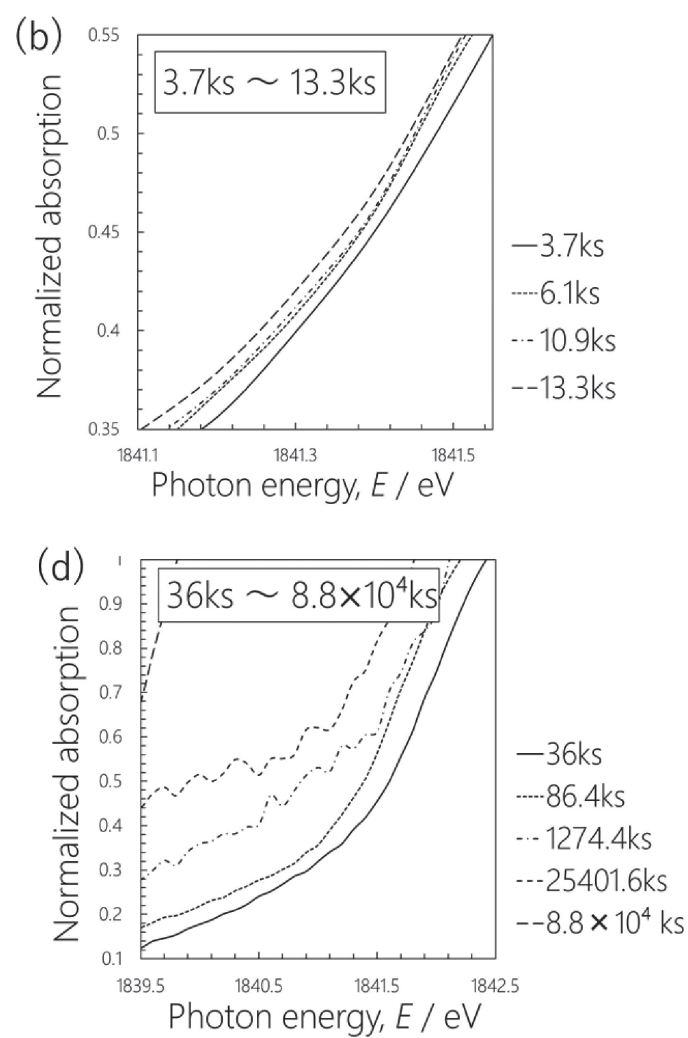

Fig. 4 Magnified XANES spectra near Si-K edge of Al-Mg-Si alloys and reference samples for NA times from (a) $0.6 \mathrm{ks}$ to $3.7 \mathrm{ks}$, (b) $3.7 \mathrm{ks}$ to $13.3 \mathrm{ks}$, (c) $13.3 \mathrm{ks}$ to $36 \mathrm{ks}$, and (d) $36 \mathrm{ks}$ to $8.8 \times 10^{4} \mathrm{ks}$.

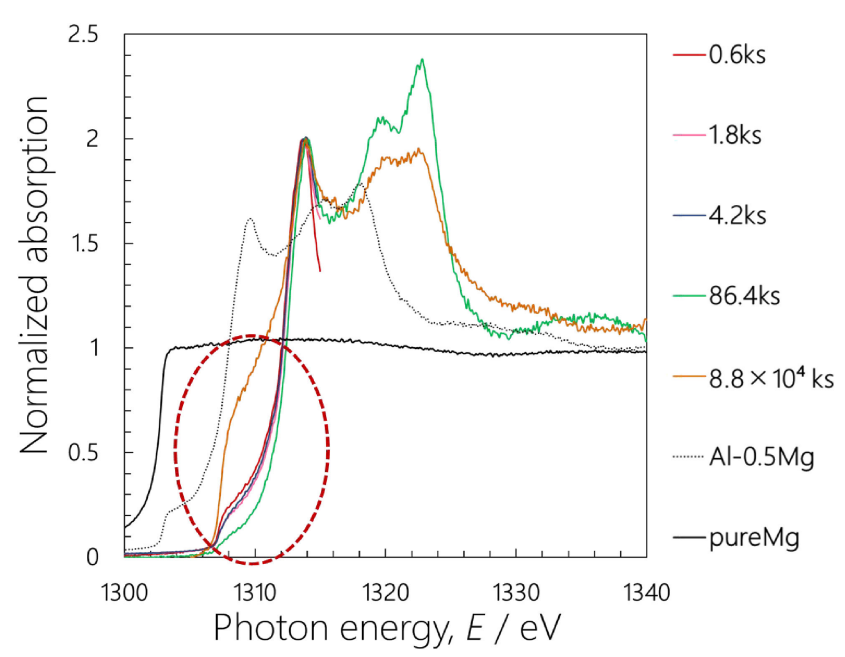

Fig. 5 XANES spectra near $\mathrm{Mg}-\mathrm{K}$ edge of $\mathrm{Al}-\mathrm{Mg}-\mathrm{Si}$ alloys and reference samples.

1.4) represent the half-distance from the central atoms to the first-nearest-neighbor atoms and the region indicated by arrows, which represent the half-distance from the central atoms, is considered the valence density of the central $\mathrm{Si}$ and $\mathrm{Mg}$ atoms. In Fig. 8(a), in the case of a central Si atom, the valence electron density of $\mathrm{Si}$ atoms increases when the firstneighbor atom is changed from an $\mathrm{Al}$ atom to an $\mathrm{Mg}$ atom. By contrast, the valence electron density of a central Si atom decreases when the first-neighbor atom is changed from an $\mathrm{Al}$ atom to an $\mathrm{Si}$ atom or to a vacancy. Most importantly, the results clarify that the valence electron density of a central $\mathrm{Si}$ atom exhibits the largest decrease when a $\mathrm{Va}$ is adjacent it.
Figure 8(b) shows that, in the case of a central $\mathrm{Mg}$ atom, the valence electron density of a $\mathrm{Mg}$ atom increases when the first-neighbor atom is changed from an $\mathrm{Al}$ atom to a $\mathrm{Si}$ atom. However, the valence electron density of a $\mathrm{Mg}$ atom decreases when the first-neighbor atom is changed from an $\mathrm{Al}$ atom to a $\mathrm{Mg}$ atom or to a Va. These results clarify that the valence electron density of a central $\mathrm{Mg}$ atom exhibits the greatest decrease when a Va is adjacent to it. Thus, the valence electron density of $\mathrm{Si}$ atoms and $\mathrm{Mg}$ atoms exhibit the greatest decreases when $\mathrm{Si}-\mathrm{Va}$ and $\mathrm{Mg}-\mathrm{Va}$ pairs are formed, respectively. Moreover, compared with Fig. 8(a) and (b), the $\mathrm{Mg}-\mathrm{Va}$ pairing results in the lowest valence electron density of $\mathrm{Mg}$ atoms among all of the pair combinations. Also, even when the number of atoms comprising a cluster is increased, the valance electron density exhibits the largest decrease compared to the $\mathrm{Si}-\mathrm{Al}$ and $\mathrm{Mg}-\mathrm{Al}$ pairs when vacancies are adjacent to the central $\mathrm{Si}$ atom or $\mathrm{Mg}$ atom.

Figure 9 shows a model of cluster formation during NA; this model is based on the change in absorption edge energy and the results of valence electron density calculations. In stage I, the valence of $\mathrm{Si}$ atoms and $\mathrm{Mg}$ atoms increases. This phenomenon is caused by the formation of $\mathrm{Si}-\mathrm{Va}$ pairs and $\mathrm{Mg}-\mathrm{Va}$ pairs, in which $\mathrm{Si}$ atoms and $\mathrm{Mg}$ atoms bind vacancies immediately after A.Q. and the valence electron density of the $\mathrm{Si}$ and $\mathrm{Mg}$ atoms decreases. Also, the formation of $\mathrm{Va}-\mathrm{Si}-\mathrm{Va}$, $\mathrm{Va}-\mathrm{Mg}-\mathrm{Va}, \mathrm{Mg}-\mathrm{Va}-\mathrm{Mg}-\mathrm{Va}$, and $\mathrm{Si}-\mathrm{Va}-\mathrm{Si}-\mathrm{Va}$ clusters that contain multiple vacancies should be considered in addition to the formation of $\mathrm{Si}-\mathrm{Va}$ and $\mathrm{Mg}-$ Va pairs.

In stage II, the valence of $\mathrm{Si}$ atoms and $\mathrm{Mg}$ atoms decreases. This phenomenon is caused by the desorption of 

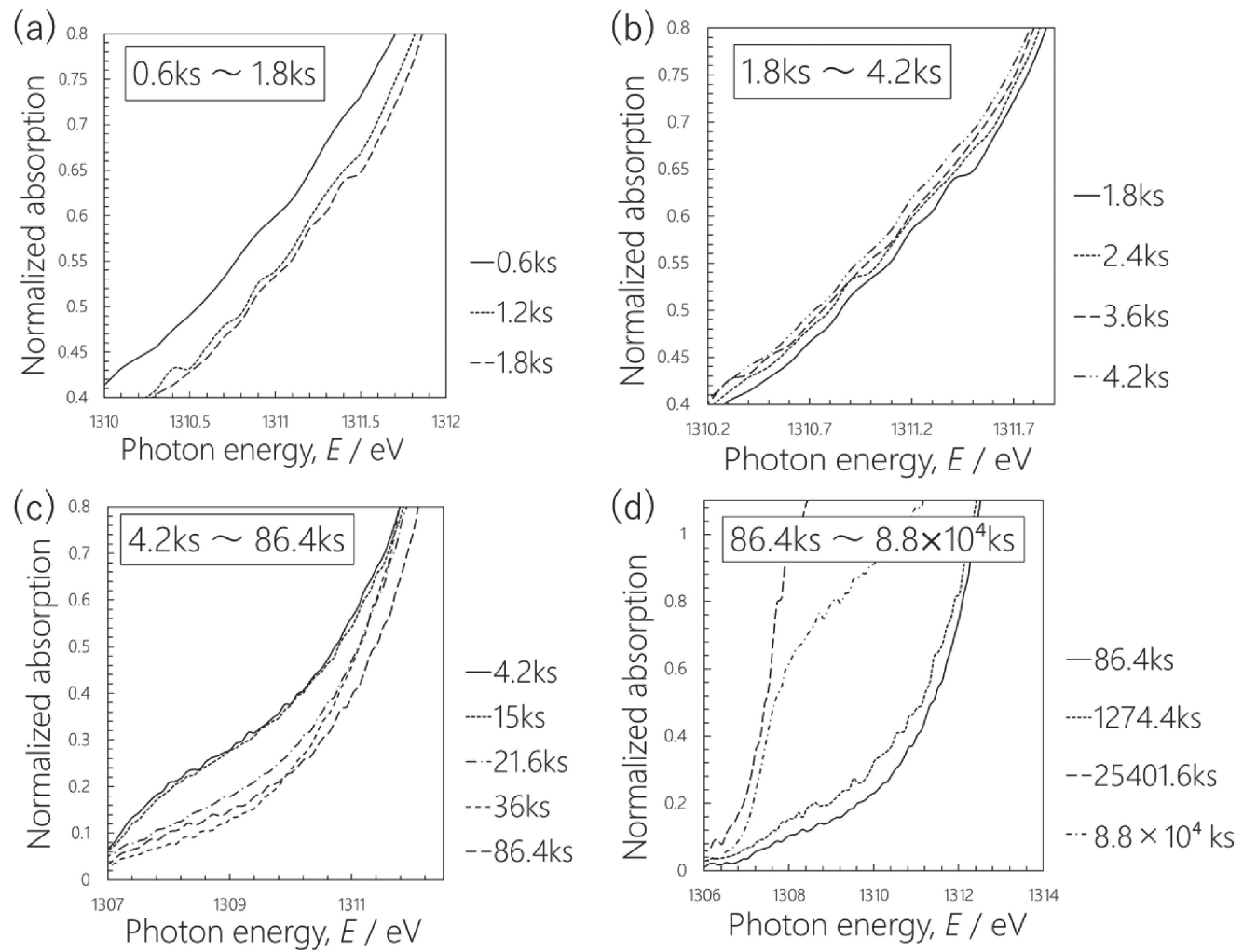

Fig. 6 Magnified XANES spectra near Mg-K edge of Al-Mg-Si alloys and reference samples for NA times from (a) $0.6 \mathrm{ks}$ to $1.8 \mathrm{ks}$, (b) $1.8 \mathrm{ks}$ to $4.2 \mathrm{ks}$, (c) $4.2 \mathrm{ks}$ to $86.4 \mathrm{ks}$, and (d) $86.4 \mathrm{ks}$ to $8.8 \times 10^{4} \mathrm{ks}$.

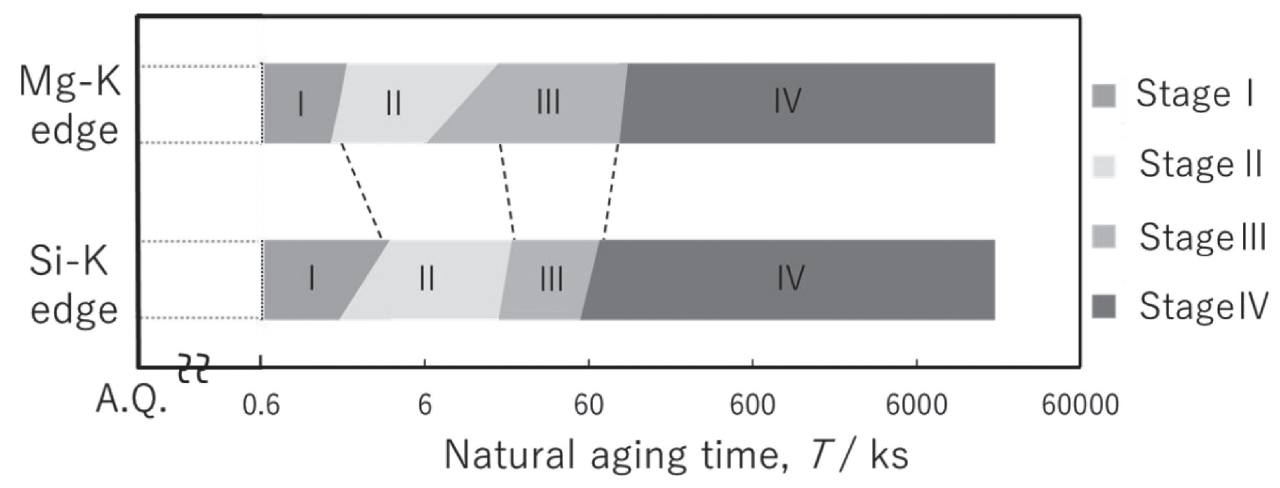

Fig. 7 Relationship between four stages of edge energy shifts and NA time in XAFS analysis.

vacancies from the $\mathrm{Si}-\mathrm{Va}$ pairs, $\mathrm{Mg}-\mathrm{Va}$ pairs, and clusters in which multiple $\mathrm{Si}-\mathrm{Va}$ and $\mathrm{Mg}-\mathrm{Va}$ pairs are combined during stage I and by the increase in the valence electron density of the $\mathrm{Si}$ and $\mathrm{Mg}$ atoms.

In stage III, the valence of $\mathrm{Si}$ atoms and $\mathrm{Mg}$ atoms increases again. We attributed these increases to vacancies being intermittently desorbed from clusters continuously from stage II and to numerous $\mathrm{Mg}-$ Va pairs, which exhibits the lowest valence electron density among the various pairs, merging into the clusters, where the latter effect is strongly reflected in the results. Also, because the diffusion coefficients of $\mathrm{Mg}$ atoms and $\mathrm{Si}$ atoms in an $\mathrm{Al}$ matrix at $25^{\circ} \mathrm{C}$ are $1.6 \times 10^{-23}$ and $\left.3.2 \times 10^{-23}, 31\right)$ we considered that movement of $\mathrm{Mg}-$ Va pairs in the $\mathrm{Al}$ matrix is more difficult than the movement of Si-Va pairs. We therefore speculated that the $\mathrm{Mg}-\mathrm{Va}$ pairs formed in stage I finally merged into other clusters more frequency, mainly in stage III. The aforementioned results suggest that the formation ratio of $\mathrm{Mg}-\mathrm{Va}-\mathrm{Mg}-\mathrm{Va}$ clusters in which multiple $\mathrm{Mg}-\mathrm{Va}$ pairs are combined during stage I and the formation ratio of $\mathrm{Mg}-\mathrm{Mg}-$ Va clusters during stage II is low, whereas the formation ratio of clusters that contain $\mathrm{Si}$ atoms (e.g., $\mathrm{Si}-\mathrm{Mg}-\mathrm{Va}$ clusters and $\mathrm{Si}-\mathrm{Si}-\mathrm{Va}$ clusters) in stage II is high.

Lastly, in stage IV, the valence of $\mathrm{Si}$ atoms and $\mathrm{Mg}$ atoms again decreases. We attribute this behavior to vacancies being further detached from coarsened clusters and to a further reduction in the ratio between the vacancies $\mathrm{Si} \mathrm{Mg}$ atoms in the clusters.

\subsection{Evaluation of the cluster formation process by XANES calculation}

Figure 10 shows experimental and calculated Si-K XANES spectra. The calculated spectra agree well with the experimentally recorded spectra in the range from $\sim 15 \mathrm{eV}$ 


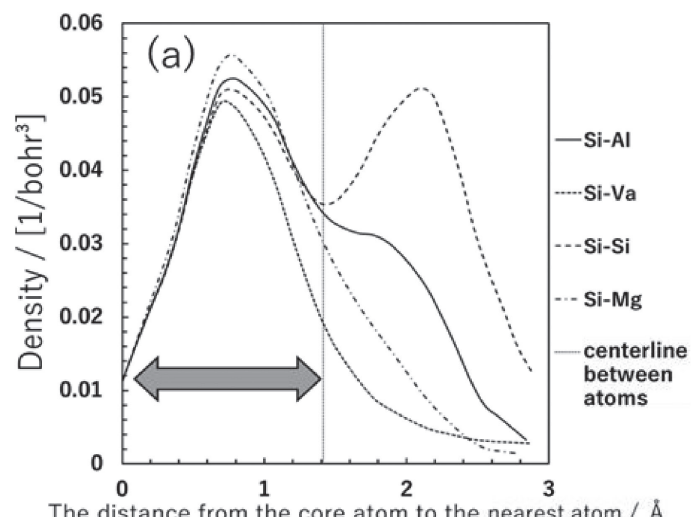

The distance from the core atom to the nearest atom / $\AA$

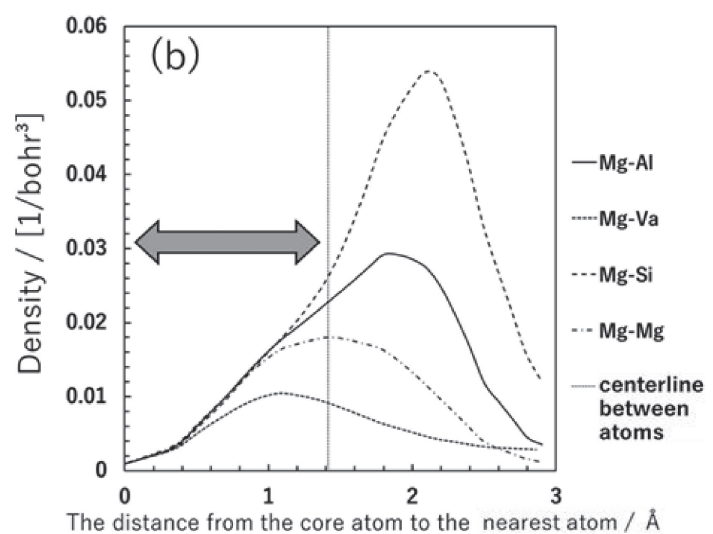

Fig. 8 Change in valence electron density from the core atom to the nearest atom for (a) central $\mathrm{Si}$ atom and (b) central $\mathrm{Mg}$ atom.

from the absorption edge to the high-energy side. We also observed that the calculated spectra vary depending on the cluster model. To compare the changes in the experimental and calculated spectra as a result of cluster formation, the subtraction was calculated based on the experimental spectrum corresponding to an NA time of $0.6 \mathrm{ks}$ in the experimental results and the calculation spectrum corre-

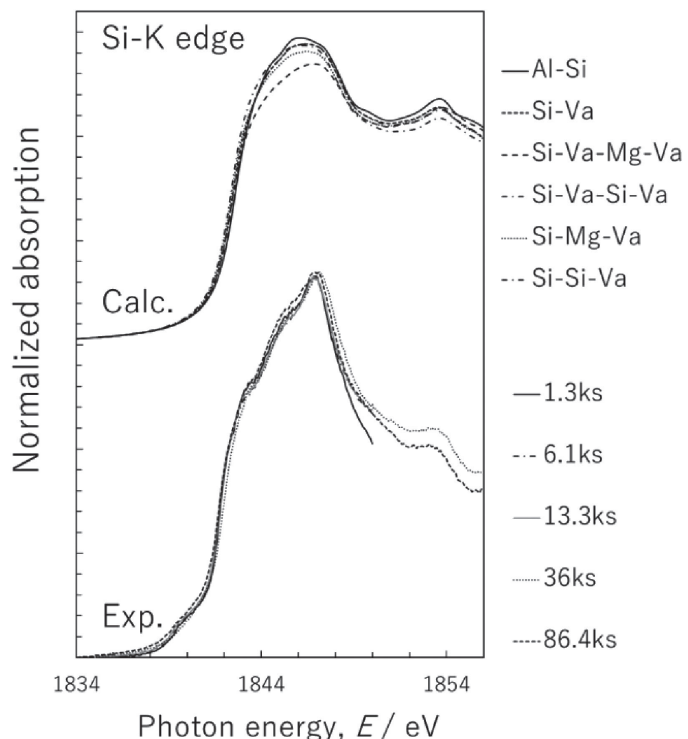

Fig. 10 Relationship between XANES spectra and calculated spectra near Si-K edge.

sponding to the calculated spectrum for the Al-Si (Al107Si1) cluster model in the calculation results. Figure 11 shows the XANES subtraction spectra and the calculated subtraction spectra near the Si-K edge in stage I and stage II. According to the calculation results in Fig. 11(a), peak (1) formed at $\sim 1842 \mathrm{eV}$ because of the formation of $\mathrm{Si}-\mathrm{Va}, \mathrm{Si}-\mathrm{Va}-\mathrm{Mg}-\mathrm{Va}$, and $\mathrm{Si}-\mathrm{Va}-\mathrm{Si}-\mathrm{Va}$ clusters, and peak (2) was formed near $1845 \mathrm{eV}$ because of the formation of $\mathrm{Si}-\mathrm{Va}-\mathrm{Mg}-\mathrm{Va}$ clusters. However, in the experimental spectra, peak (1) appeared. Peak (2) increased in intensity when the aging time was increased to $4.2 \mathrm{ks}$. Therefore, the inference from the changes in absorption edge energy is consistent with the formation of $\mathrm{Si}-\mathrm{Va}, \mathrm{Si}-\mathrm{Va}-\mathrm{Mg}-\mathrm{Va}$, and $\mathrm{Si}-\mathrm{Va}-\mathrm{Si}-\mathrm{Va}$ clusters in stage I. The calculation results in Fig. 11(b) show the emergence of peak (1) at $\sim 1842 \mathrm{eV}$ because of the formation of $\mathrm{Si}-\mathrm{Si}-\mathrm{Va}$

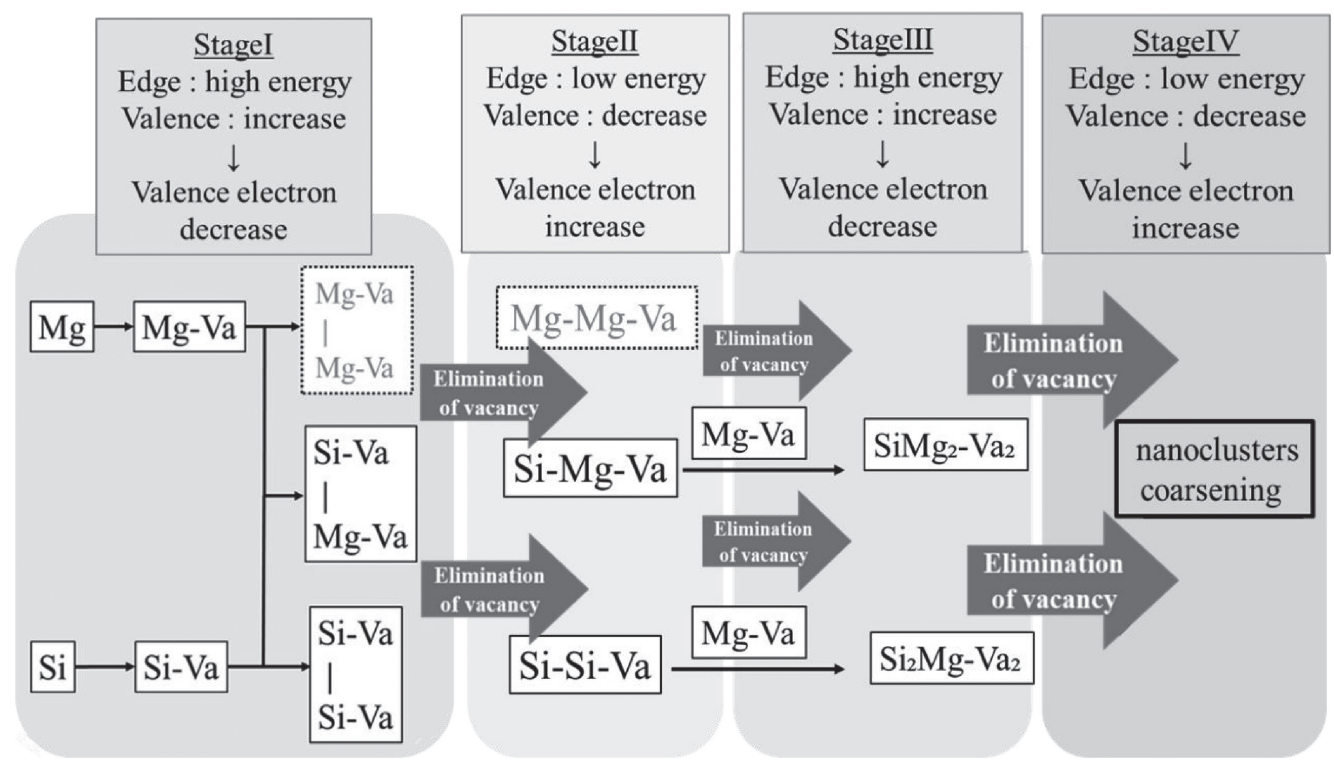

Fig. 9 Model of cluster formation during NA. Stage I: Formation of Si-Va pairs, Mg-Va pairs, and combination of Si-Va and Mg-Va pairs. Stage II: Release of vacancies from clusters formed in stage I. Stage III: Inclusion of Mg-Va pairs in clusters. Stage IV: Coarsening of clusters by release of vacancies. 
(a) Stage I

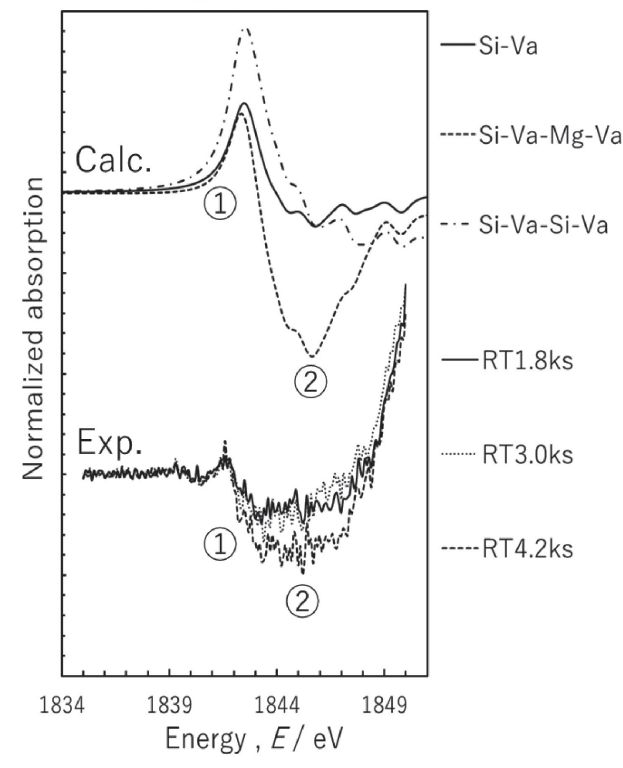

(b) Stage II

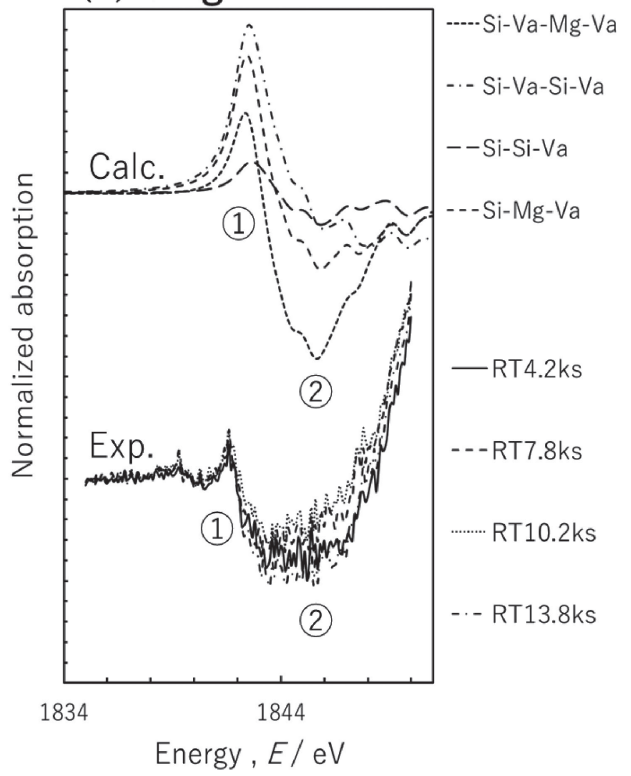

Fig. 11 Relationship between XANES subtraction spectra and calculated subtraction spectra near Si-K edge in (a) stage I and (b) stage II.

The criterion for the XANES subtraction spectra is $0.6 \mathrm{ks}$ and that for the calculated subtraction spectra is the Al107Sil model.

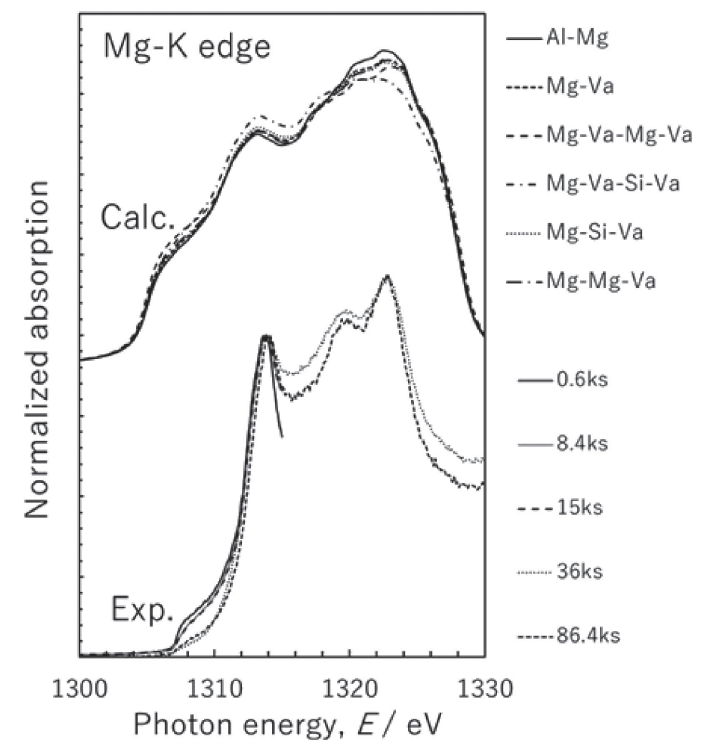

Fig. 12 Relationship between XANES spectra and calculated spectra near Mg-K edge.

and $\mathrm{Si}-\mathrm{Mg}-\mathrm{Va}$ clusters and peak (2) at $\sim 1845 \mathrm{eV}$ because of the formation of Si-Mg-Va clusters. Peak (1) and peak (2) also appeared in the experimental spectrum. Therefore, given that $\mathrm{Si}-\mathrm{Si}-\mathrm{Va}$ and $\mathrm{Si}-\mathrm{Mg}-\mathrm{Va}$ clusters were formed in stage II, the results are consistent with the inference from the changes in the absorption edge energy.

Figure 12 shows the experimental and calculated $\mathrm{Mg}-\mathrm{K}$ XANES spectra. The calculated spectra are in good agreement with the experimental spectra in the range from $\sim 20 \mathrm{eV}$ from the absorption edge to the high-energy side. In addition, the calculated spectra changed because of the difference in the cluster models. To compare the changes in the experimental spectra and the spectra calculated on the basis of the cluster models, we subtracted the experimental spectrum corresponding to an NA time of $0.6 \mathrm{ks}$ and the calculated spectrum for the $\mathrm{Al}-\mathrm{Mg}$ (A1107Mg1) cluster model.

Figure 13 shows the XANES subtraction spectra and the calculated subtraction spectra near the $\mathrm{Mg}-\mathrm{K}$ edge in stage I and stage II. According to the calculation results in Fig. 13(a), peak (1) appeared at $\sim 1308 \mathrm{eV}$ and peak (2) appeared at $\sim 1314 \mathrm{eV}$ because of the formation of $\mathrm{Mg}-\mathrm{Va}$, $\mathrm{Mg}-\mathrm{Va}-\mathrm{Si}-\mathrm{Va}$, and $\mathrm{Mg}-\mathrm{Va}-\mathrm{Mg}-\mathrm{Va}$ clusters. However, in the calculated spectrum of the $\mathrm{Mg}-\mathrm{Va}-\mathrm{Mg}-\mathrm{Va}$ cluster, the intensity of peak (1) was approximately three times greater than that of peak (2), whereas in the experimental spectrum, peak (1) was weak and the intensity of peak (2) increased when the aging time was increased to $1.8 \mathrm{ks}$. Therefore, given that the formation of $\mathrm{Mg}-\mathrm{Va}-\mathrm{Mg}-\mathrm{Va}$ clusters was difficult but $\mathrm{Mg}-\mathrm{Va}$ pairs and $\mathrm{Mg}-\mathrm{Va}-\mathrm{Si}-\mathrm{Va}$ clusters formed easily in stage I, the results are consistent with the inference from the changes in the absorption edge energy. According to the calculation results in Fig. 13(b), peak (1) appeared at $\sim 1308 \mathrm{eV}$ and peak (2) appeared at $\sim 1314 \mathrm{eV}$ because of the formation of $\mathrm{Mg}-\mathrm{Si}-\mathrm{Va}$ and $\mathrm{Mg}-\mathrm{Mg}-\mathrm{Va}$ clusters. The calculated spectrum of $\mathrm{Mg}-\mathrm{Mg}-\mathrm{Va}$ clusters shows that the intensity of peak (1) was approximately twice that of peak (2). By contrast, in the experimental spectrum, peak (1) was weak and the intensity of peak (2) tended to decrease with increasing aging time. Therefore, because the formation of $\mathrm{Mg}-\mathrm{Mg}-\mathrm{Va}$ clusters was difficult and $\mathrm{Mg}-\mathrm{Si}-\mathrm{Va}$ clusters formed easily in stage II, the results are consistent with the inference from the changes in the absorption edge energy.

\section{Conclusion}

We evaluated the cluster formation behavior during NA after solution treatment by conducting soft-X-ray XAFS measurements of excess-Si-type Al-1.04Si-0.55Mg (mass\%) alloys. 

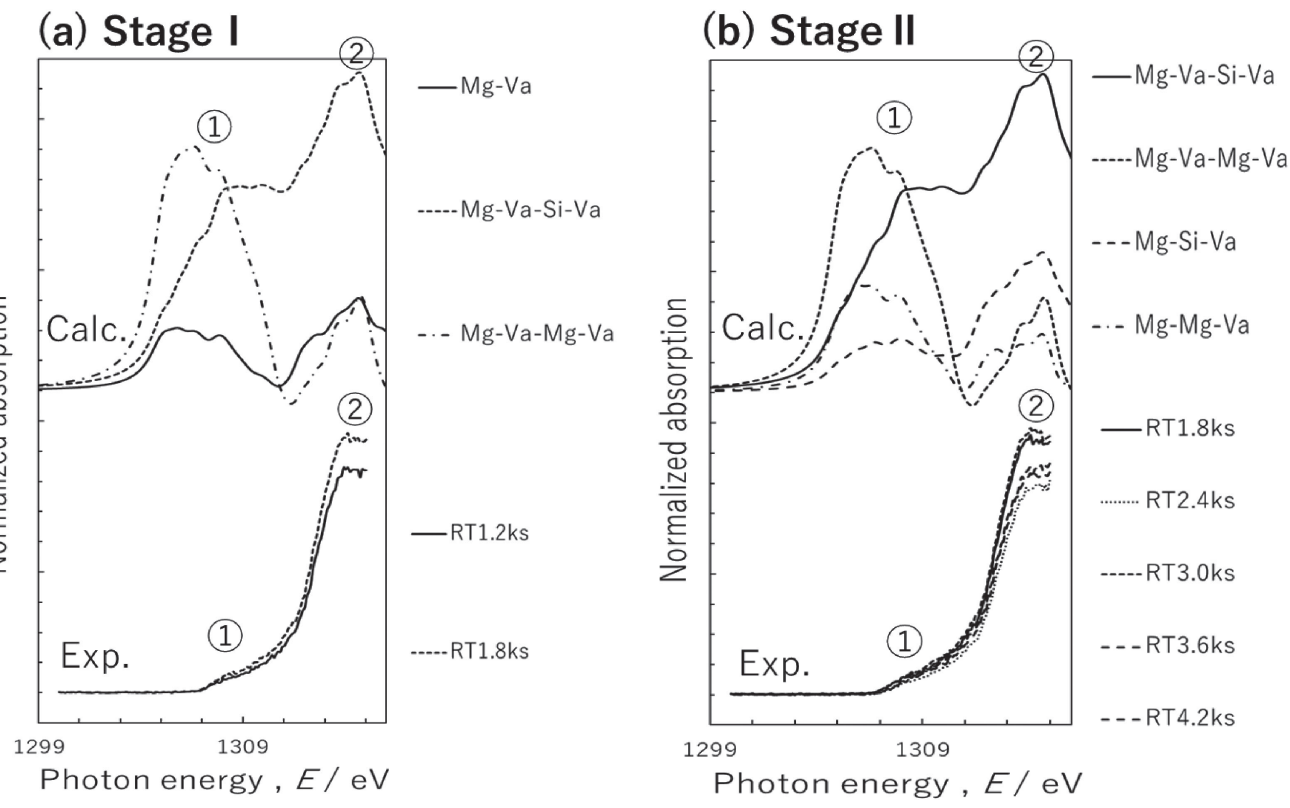

Fig. 13 Relationship between XANES subtraction spectra and calculated subtraction spectra near Mg-K edge in (a) stage I and (b) stage II. The criterion for the XANES subtraction spectra is $0.6 \mathrm{ks}$ and that for the calculated subtraction spectra is the Al107Mg1 model.

Furthermore, the cluster formation process estimated from the absorption edge energy changes and the results of changes in estimated XANES profile were compared. The conclusions are summarized as follows:

(1) The absorption edge energy of $\mathrm{Si}-\mathrm{K}$ and $\mathrm{Mg}-\mathrm{K}$ changed through four stages as NA progressed because the valence electron density of the $\mathrm{Si}$ and $\mathrm{Mg}$ atoms changed with the formation of clusters.

(2) Each stage was interpreted as follows:

Stage I: $\mathrm{Si}$ atoms and $\mathrm{Mg}$ atoms combined with vacancies to form $\mathrm{Si}-\mathrm{Va}$ pairs and $\mathrm{Mg}-\mathrm{Va}$ pairs, respectively. In addition, although clusters in which a plurality of these pairs were united could form, the clusters containing only $\mathrm{Mg}$ atoms and vacancies rarely grew.

Stage II: Vacancies were eliminated from clusters formed in stage I, such as $\mathrm{Si}-\mathrm{Va}$ pairs, $\mathrm{Mg}-$ Va pairs, and clusters in which multiple Si-Va pairs and $\mathrm{Mg}-\mathrm{Va}$ pairs were united.

Stage III: Although the vacancies were eliminated from the formed clusters, a large amount of $\mathrm{Mg}-\mathrm{Va}$ pairs merged into clusters.

Stage IV: Vacancies were eliminated from the clusters while clusters coarsened.

(3) We clarified that the behavior of Si atoms and $\mathrm{Mg}$ atoms can be evaluated individually using soft-X-ray XAFS measurements.

\section{Acknowledgments}

This research was supported by the 2019 Special Scholarship Research Fund of the Light Metal Educational Foundation. Samples were provided by UACJ Corporation. The synchrotron radiation experiment was carried out at BL27SU in SPring-8 with JASRI certification. (Issue number
2017B1772, 2018A1539, 2019A1613). The authors are very thankful for them.

\section{REFERENCES}

1) T. Sato: J. JILM 56 (2006) 592-601.

2) H. Hatta, H. Tanaka, S. Matsuda and H. Yoshida: J. JILM 54 (2004) $412-417$.

3) Y. Aruga and T. Sato: J. JILM 67 (2017) 144-150.

4) K. Yamada, T. Sato and A. Kamio: J. JILM 51 (2001) 215-221.

5) Y. Aruga, M. Kozuka, S. Kim, E. Kobayashi and T. Sato: J. JILM 68 (2018) 133-140.

6) A. Serizawa, S. Hirosawa and T. Sato: Metall. Mater. Trans. A 39 (2008) 243-251.

7) I. Dutta and S.M. Allen: J. Mater. Sci. Lett. 10 (1991) 323-326.

8) K. Fukui, M. Takeda and T. Endo: Mater. Trans. 46 (2005) 880-884.

9) B. Klobes, T.E.M. Staab and E. Dudzik: Phys. Status Solidi RRL 2 (2008) 182-184.

10) T.E.M. Staab, M. Haaks, C. Zamponi, H. Modrow and K. Maier: Phys. Status Solidi RRL 1 (2007) 172-174.

11) C.S. Tsao, U.S. Jeng, C.Y. Chen and T.Y. Kuo: Scr. Mater. 53 (2005) 1241-1245.

12) C.S. Tsao, C.Y. Chen, U.S. Jeng and T.Y. Kuo: Acta Mater. 54 (2006) $4621-4631$.

13) K. Takata, J. Takahashi, M. Saga, K. Ushioda, A. Hibino and M. Kikuchi: Mater. Trans. 55 (2014) 885-891.

14) S. Kim, J. Kim, H. Tezuka, E. Kobayashi and T. Sato: Mater. Trans. 54 (2013) 297-303.

15) J.H. Kim, E. Kobayashi and T. Sato: Mater. Trans. 52 (2011) 906-913.

16) J. Banhart, M.D.H. Lay, C.S.T. Chang and A.J. Hill: Phys. Rev. B 83 (2011) 014101.

17) M. Liu and J. Banhart: Mater. Sci. Eng. A 658 (2016) 238-245.

18) Z. Jia, L. Ding, L. Cao, R. Sanders, S. Li and Q. Liu: Metall. Mater. Trans. A 48 (2017) 459-473.

19) Y. Aruga, M. Kozuka, Y. Takaki and T. Sato: Mater. Sci. Eng. A 631 (2015) 86-96.

20) C.S. Tsao, U.S. Jeng, C.Y. Chen and T.Y. Kuo: Scr. Mater. 53 (2005) 1241-1245.

21) C.S. Tsao, C.Y. Chen, U.S. Jeng and T.Y. Kuo: Acta Mater. 54 (2006) 4621-4631.

22) T. Suzuki: Foundation and Applications of XAFS, The Japanese XAFS 
Society [compilation], (2017) pp. 3-109 (in Japanese).

23) U. Bergmann, C.R. Home, T.J. Collins, J.M. Workman and S.P. Cramer: Chem. Phys. Lett. 302 (1999) 119-124.

24) J. Garcia, G. Subias, V. Cuartero and J. H-Martin: J. Synchrotron Rad., 17 (2010) 386-392.

25) H. Adachi, H. Nakanishi and M. Asano: J. JILM 65 (2015) 411-415.

26) D.S. Sholl and J.A. Steckel [T. Sasaki and S. Suehara, Co-translation] Density Functional Theory A Practical Introduction (Yoshiokashoten,
Kyoto, 2018) (in Japanese).

27) T. Mizoguchi: Materia Japan 46 (2007) 427-431.

28) H. Ikeno and T. Mizoguchi: KENBIKYO 50 (2015) 16-22.

29) T. Mizoguchi, E. Tochigi, N. Shibata, Y. Ikuhara and K. Matsunaga: Materia Japan 53 (2014) 414-418.

30) J. Yamauchi: Hyomen Kagaku 28 (2007) 135-143.

31) K. Hirano: J. JILM 29 (1979) 249-262. 